ISSN 1996-1073

www.mdpi.com/journal/energies

Article

\title{
System Identification and Integration Design of an Air/Electric Motor
}

\author{
Yean-Ren Hwang * and Shih-Yao Huang \\ Department of Mechanical Engineering, National Central University, 300 Jhong-Da Road, Chong-Li \\ 32001, Taiwan; E-Mail: kejsu@yahoo.com.tw
}

* Author to whom correspondence should be addressed; E-Mail: yhwang@cc.ncu.edu.tw; Tel.: +886-3-422-7151 (ext. 34342); Fax: +886-3-425-4501.

Received: 5 December 2012; in revised form: 4 February 2013 / Accepted: 5 February 2013 / Published: 8 February 2013

\begin{abstract}
This paper presents an integration design and implementation of an air motor and a DC servo motor which utilizes a magnetic powder brake to integrate these two motors together. The dynamic model of the air/electric hybrid system will be derived and eventually leads to successful ECE-40 driving cycle tests with a FPGA-based speed controller. The testing results obtained by using the proposed experimental platform indicate that the total air consumption is about $256 \mathrm{~L}$ under air motor mode and the electric charge consumption is about 530 coulombs under DC servo motor mode. In a hybrid mode, the current reduction of the battery is about $18.5 \%$, and then the service life of the battery can be improved. Furthermore, a prototype is built with a proportional-integral (PI) speed controller based on a field-programmable gate array (FPGA) in order to facilitate the entire analysis of the velocity switch experiment. Through the modular methodology of FPGA, the hybrid power platform can successfully operate under ECE-40 driving cycle with the PI speed controller. The experimental data shows that the chattering ranges of the air motor within $\pm 1 \mathrm{~km} / \mathrm{h}$ and $\pm 0.2 \mathrm{~km} / \mathrm{h}$ under DC servo motor drive. Therefore, the PI speed controller based on FPGA is successfully actualized.
\end{abstract}

Keywords: air motor; DC servo motor; hybrid system; field programmable gate array 


\section{Introduction}

Currently in Taiwan, there are more than 15 million motorcycles, mostly driven by internal combustion engines (ICEs) [1]. As a result, great amounts of air pollutants are generated by motorcycles and then released into the atmosphere, and this is one of the major reasons causing global warming and dramatic climate change. In order to improve this phenomenon, vehicles propelled by electric motors are an alternative scheme to replace the ICEs. Besides, the studies estimated that in 2030, pure electric vehicles will account for about $16 \%$ of all automotive sales [2]. Hence, the importance of the electric vehicle (EV) development is constantly getting more and more attention.

Electric motors are widely used in the automation industry, as they have several advantages of good precision, cleanliness, quiet, and ease of implementation [3]. In addition, electric motors produce no exhaust emissions in their immediate environment. However, they also suffer from the drawbacks of the battery system when used in automotive applications. When the electric vehicles operate under standing start or accelerate conditions, the battery system will be operating in the large discharge region and this will shorten the service life. As it is well known, the battery system is one of the weakest points of electric vehicles, as well as usually being the most expensive component [4]. In order to extend the service life of the battery system and reduce the cost, auxiliary power is needed to help the battery system avoid operating in the large discharge region.

In this paper, for the green energy conception, we propose an integration design of an air motor and an electric motor based on a field programmable gate array (FPGA) controller. Since the emission of an air motor is air, there will be no air pollutants released into the atmosphere, and this feature corresponds well with the electric motors. Air motors produce very high specific power. They require compressed air rather than electricity, thus avoiding sparks and can be used in demanding environments. One drawback of air motors is that they are less efficient than their electric counterparts. Typically, an electric motor drives an air compressor, which supplies the air to drive an air motor. The efficiency of the system is usually less than $20 \%$. The efficiency of fractional horsepower induction motors is usually from $45 \%$ to $70 \%$ when they are fully loaded. Most electric motors, however, do not run fully loaded; the efficiencies actually experienced are thus lower than these maximums. The point here is that air motors are selected over electric motors not for their efficiencies but, rather, for their many other features [5-9]. Nowadays, there are several types of hybrid system being developed. Takemura et al. proposed a hybrid pneumatic/electric motor, so that the hybrid actuator has better damping and ease of control than the pneumatic motor [10]. Tzeng et al. presented other hybrid pneumatic power for motorcycles to investigate and develop the pneumatic motor combined with an ICE [11]. Hsu and Lu also presented a hybrid management system in motorcycles to investigate and develop the electric motor combined with an ICE [12]. Generally, the main purpose of the hybrid system is to achieve either better fuel economy or better performance than a conventional solution.

In the speed controller design, there are two major solutions: one is the field programmable gate array (FPGA) and the other is the digital signal processor (DSP). FPGA is combined with low cost, convenient software tools and significant integration density. The advantage of DSP is that it is good at heterogeneous functions, whereas FPGA is suitable for the high level of parallelism of the algorithm [13]. Based on the multiple-sensor application, we have developed a FPGA control system for an air/electric hybrid system. The FPGA is typically programmed in hardware description language (HDL) that 
includes very high speed integrated circuit hardware description language (VHDL) and Verilog coding styles. In the design style, the modular conception is used to divide a complex system into many subsystems. This top-down methodology shortens the development time and makes it easy to modify each module. Each module has its specific function and could be programmed in VHDL or Verilog, depending on the user's experience. Since the HDL can be used in application specific integrated circuit (ASIC), FPGA or complex programmable logic device (CPLD) without modifying it, the HDL is the main stream for digital logic design.

The major contributions of this research are as follows: in order to achieve the concept of green energy, an air/electric hybrid power system is presented in this paper. A PI speed controller based on FPGA is also developed to accomplish the ECE-40 driving cycle test. The efficiency of the overall system will be analyzed through the experiment data. The remaining sections are organized as follows: the following section presents experimental setup and the test platform. Thereafter, the system identification of hybrid air/electric motor is discussed, then the experimental results are shown and analyzed and finally, the conclusions are drawn.

\section{Experimental Setup and the Test Platform}

Figure 1 shows the schematic diagram of the platform constructed for experiments on the proposed hybrid power system. When the hybrid power platform is started and rotated at low speed, the FPGA board receives the speed signals from optical encoder and then sends the digital signals out to control the proportional servo valve through the digital to analog converter (DAC) so that the air motor is a driving source. Therefore, the flow path of compressed air starts from high pressure air tank, go through the regulator, control valve, flow meter, pressure sensor, and then finally enters the air motor. As the hybrid power platform speed increases and finally reaches the switching point, the DC servo motor start rotates and its speed controlled by the FPGA controller through the driver circuit. In order to accomplish the European driving cycle (ECE-40) test of the hybrid power platform, the following major components will have to be implemented.

Figure 1. Control procedure of an air-electric power hybrid system.

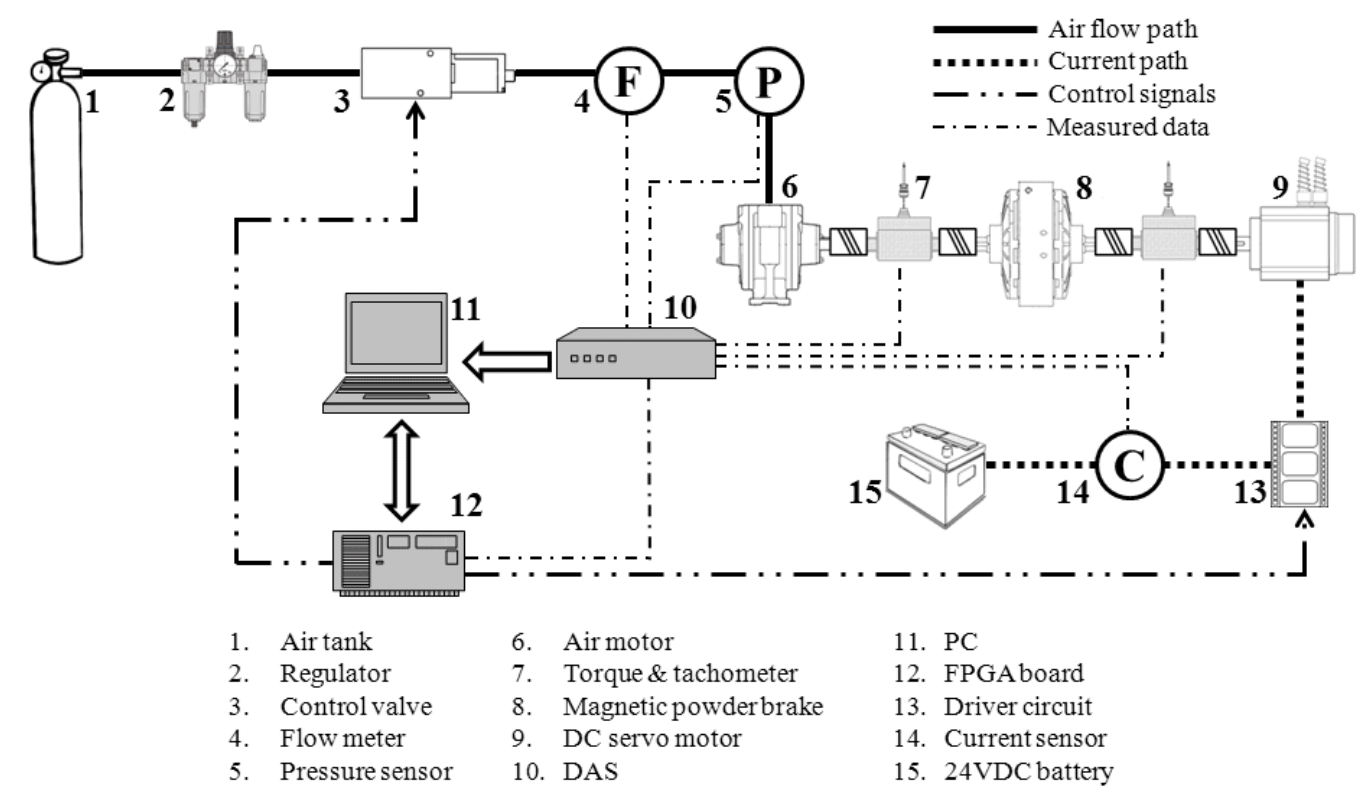




\subsection{Vane-Type Air Motor}

Rotary air motors work by transforming the potential energy of compressed air into rotary power. Compared to electric motors, air motors are cleaner, safer, have a higher power-to-weight ratio, and have better compliance and resistance to environmental damages. In addition, vane-type air motors can produce a wide range of torque and speed levels. A vane-type air motor (GAST company) is selected in this research, which is rated at power of $3 \mathrm{~kW}$, a largest torque of $12.7 \mathrm{Nm}$, and a maximum rotational speed of $3000 \mathrm{rpm}$. The high pressure air tank is utilized as the power source for the air motor and its capacity is $6000 \mathrm{~L}$.

\subsection{Servo Motor}

DC servo motors are normally used as prime movers in computers, numerically controlled machinery, or other applications where starts and stops are made quickly and accurately. Servo motors have lightweight, low-inertia armatures that respond quickly to excitation-voltage changes. A King Right $24 \mathrm{~V}$ DC servo motor is selected, which is rated at power of $700 \mathrm{~W}$, a largest torque of $2 \mathrm{Nm}$, and a maximum rotational speed of $1500 \mathrm{rpm}$. One set of motor drive controller is used to receive FPGA control command and to drive the DC motor. The $12 \mathrm{~V}-80 \mathrm{Ah}$ lead-acid batteries are utilized as the power source for the DC motor.

\subsection{Magnetic Powder Brake}

Electromagnetic brakes slow or stop motion using electromagnetic force to apply mechanical resistance. Electromagnetic brakes have many types, such as single face brake, power off brake, particle brake, etc. In this paper, a magnetic powder brake is selected and its main task was its use as the external load and to connect motors together in hybrid power platform. Magnetic powder brakes are unique from other electro mechanical brakes because of the wide operating torque range available. Magnetic particles are located in the powder cavity. When electricity is applied to the coil, the resulting magnetic flux tries to bind the particles together. As the electric current is increased, the binding of the particles becomes stronger.

\subsection{Data Acquisition}

In order to analyze the performance of an air motor and a DC servo motor, efficiency is one of the most important indicators. The efficiency of a motor is defined as the ratio of the output shaft power to the input power, Equations (1) and (2) represents the efficiency of an air motor and a DC servo motor, respectively:

$$
\begin{gathered}
\eta_{a i r}=\frac{\omega T}{\Delta p Q} \\
\eta_{d c}=\frac{\omega T}{I V}
\end{gathered}
$$

According to this definition, the measured data include the angular velocity ( $\mathrm{rad} / \mathrm{s})$, torque $(\mathrm{kgf} \mathrm{cm})$, different pressures from inlet port to outlet port $\left(\mathrm{kgf} / \mathrm{cm}^{2}\right)$, the air flow value under compressed condition $\left(\mathrm{cm}^{3} / \mathrm{s}\right)$, current $(\mathrm{A})$ and voltage $(\mathrm{V})$ of the batteries. Hence, these physical data must be 
measured by various sensors and converted into electrical signals that can be read by data acquisition system. A personal computer with a Model-100 data acquisition device is used in this research to gather the operating data for hybrid power platform testing. The sensors of the hybrid power platform and their specifications are listed in Table 1.

Table 1. The sensors of the hybrid power platform.

\begin{tabular}{ll}
\hline Element & Function and specification \\
\hline Rotary optical encoder & $\begin{array}{l}\text { Converts the angular motion to a digital code and the resolution is } \\
1000 \text { pulses per revolution. }\end{array}$ \\
Pressure transducer & $\begin{array}{l}\text { It generates a voltage signal as a function of the pressure imposed } \\
\text { and the range is } 0 \text { to } 200 \text { psig (pound-force per square inch gauge) } \\
\text { Converts a torsional mechanical input into a voltage output signal } \\
\text { and its range is } 0 \text { to } 100 \mathrm{Nm} .\end{array}$ \\
Torque sensor & $\begin{array}{l}\text { Measures mass flow rate of a fluid traveling through a tube and its } \\
\text { sensed range is } 0 \text { to } 200 \text { slm. } \\
\text { Mass flow meter }\end{array}$ \\
Current sensor & $\begin{array}{l}\text { petects electrical current in a wire and generates a voltage signal } \\
\text { proportional to it. The sensed current range is } 0 \text { to } 57 \text { A. }\end{array}$ \\
\hline
\end{tabular}

\section{System Identification of Hybrid Air/Electric Motor}

The concept of a hybrid system is to use the DC servo motor as the main actuation source and the air motor as the auxiliary device. As shown in Figure 2, the air motor and the DC servo motor are arranged in parallel, and between these two motors we use the powder brake as the external load. In the following section, we derive the dynamics of the hybrid power platform.

Figure 2. The experimental air-electric power hybrid system.

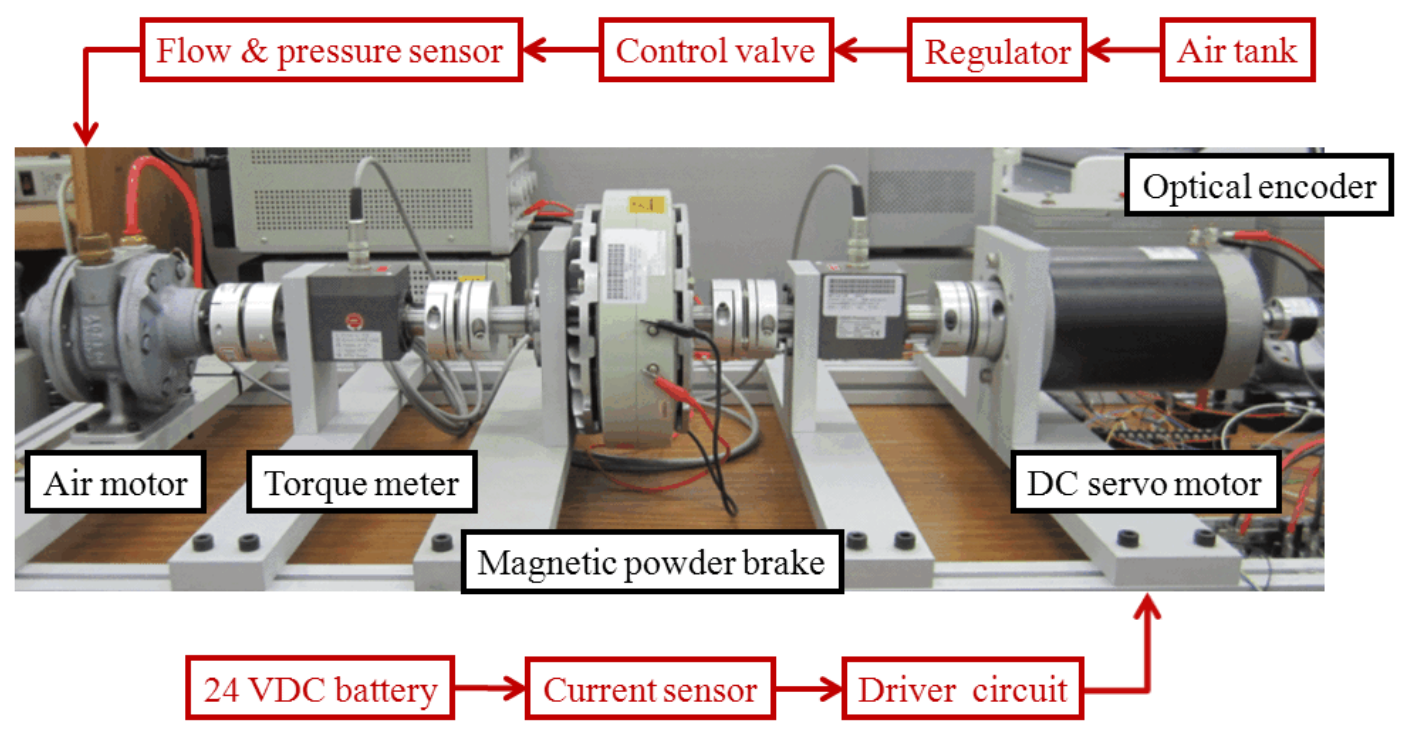


A schematic representation of an armature controlled DC motor is given in Figure 3. For an armature controlled DC motor, the field current is constant and the torque $T$ generated at the DC motor shaft is shown in Equation (3):

$$
T(t)=K_{T} i_{a}(t)
$$

In Equation (3), $K_{T}$ is the given motor torque constant ( $\left.\mathrm{Nm} / \mathrm{A}\right)$ and $i_{a}$ is the armature current (A). Note that for an armature controlled DC motor, the back electromotive force $e_{b}$ induced in the armature due to armature rotation is directly proportional to the armature angular velocity. Next, the differential equation relating the armature current $i_{a}$ and the back e.m.f. $e_{b}$ to the armature voltage $e_{a}$ can be obtained by applying Kirchhoff's voltage law (KVL). Thus, Equation (4) shows the representation of the armature voltage $e_{a}$ according to the KVL:

$$
L_{a} \frac{d i_{a}(t)}{d t}+R_{a} i_{a}(t)+e_{b}(t)=e_{a}(t)
$$

Figure 3. A schematic representation of an armature controlled DC motor.

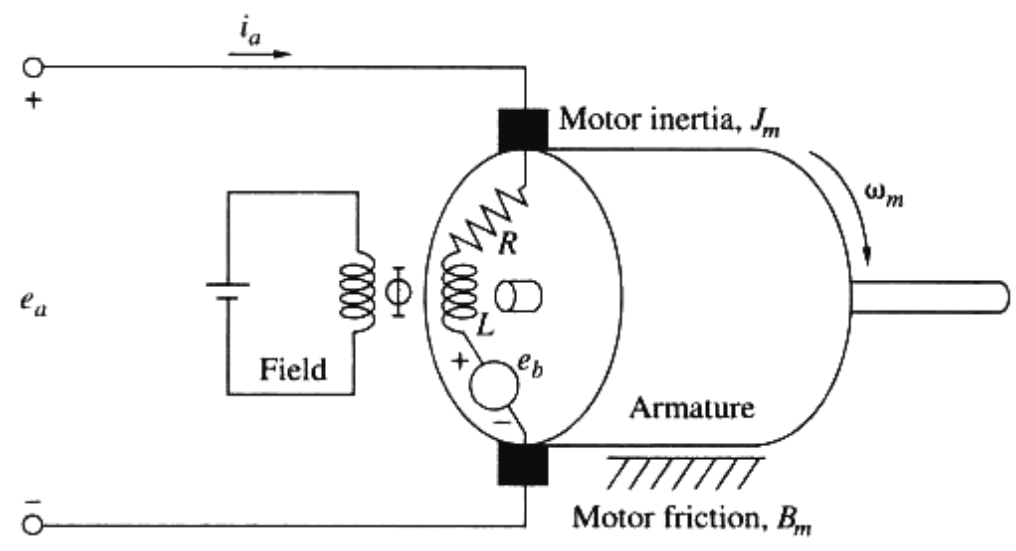

In order to increase the damping response, a low inductance material is usually selected for the DC motor. Therefore, the armature inductance can be neglected during the derivation of the DC servo motor model. In addition, Newton's second law of angular motion is also considered and shown in Equation (5). In Equation (5), the $J_{d c}$ and $B_{d c}$ are the inertia and viscosity coefficient of DC servo motor, respectively. Now, taking the Laplace transform of Equations (3)-(5) and then Equation (6) will be derived which represents the first-order transfer function model which relates the DC motor angular velocity response to the armature voltage input. For simplicity, the DC servo motor transfer function model can be equivalently by two parameters which are $K_{d c}$ and $T_{d c}$, represents the dc-gain and the mechanical time constant of the DC servo motor, respectively:

$$
\begin{gathered}
T(t)=J_{d c} \frac{d \omega(t)}{d t}+B_{d c} \omega(t) \\
G_{d c}(s)=\frac{\omega(s)}{e_{a}(s)}=\frac{K_{T} / K_{E} K_{T}+R_{a} B_{d c}}{R_{a} J_{d c} / K_{E} K_{T}+R_{a} B_{d c} s+1}=\frac{K_{d c}}{T_{d c} s+1}
\end{gathered}
$$

In order to determine the approximate values of dc-gain and time constant, we analyze the system's response to known inputs. Figure 4 shows the open loop response of DC servo motor. Notice that the 
graph's shape is consistent with the exponential response, so the DC servo motor system could be approximated by a first order system. Using the steady-state angular velocity and the time constant we have estimated, the dynamics of the DC servo motor is shown in the Equation (7) and the model error between $0.3 \%$ and $3 \%$ :

$$
G_{d c}(s)=\frac{\omega(s)}{e_{a}(s)}=\frac{K_{d c}}{T_{d c} s+1}=\frac{370.77}{0.8435 s+1}
$$

Figure 4. Open loop response of DC servo motor.

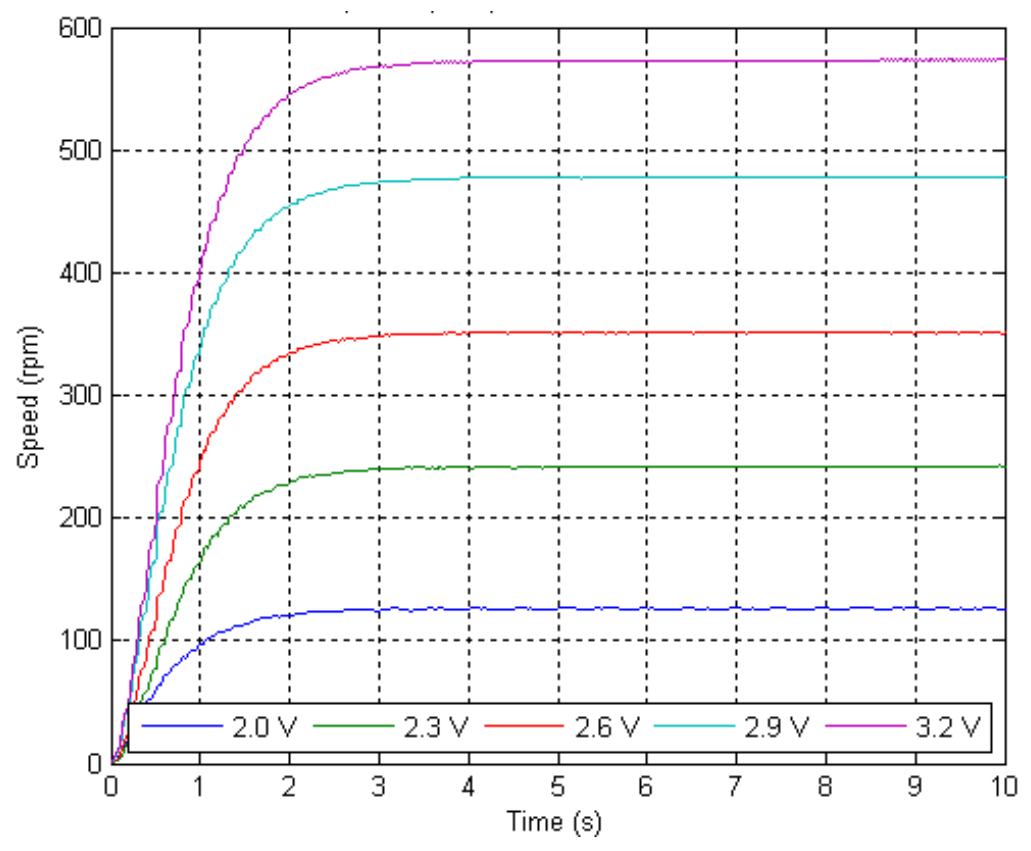

Next, the dynamics of a vane-type air motor can be expressed as in Equation (8) by Newton's second law of angular motion. In Equation (8), $J_{\text {air }}$ and $B_{\text {air }}$ are the inertia and viscosity coefficient, $P_{i}$ and $P_{o}$ are pressures at input and output ports, $P_{a}$ is the atmosphere pressure, $V_{i}$ and $V_{o}$ are volumes at input and output chambers. The drive torque $T$ is determined by the difference of the pressure acting on the vane between the drive and exhaust chambers:

$$
J_{\text {air }} \frac{d \omega(t)}{d t}+B_{\text {air }} \omega(t)=T(t)=\left(P_{i}-P_{a}\right) V_{i}-\left(P_{o}-P_{a}\right) V_{o}
$$

During the control experiment, the angular speed is determined by two factors which are air pressure and air flow rate. Under the fixed gauge pressure condition, the air flow rate is the only control variable. Thus, we can change the input voltage of the proportional servo valve to adjust the air flow rate and then accomplish the speed control of an air motor. Figure 5 shows the linear relationship between input voltage and air pressure difference under the constant supply pressure. Therefore, the assumption used in this research in order to simply the model process is that the drive torque $T$ is proportional to the input voltage and is shown in Equation (9), where $K_{T}$ is the torque constant. As for the operating range of the proportional servo valve, the air flow rate is $0 \%$ when the input voltage is $5 \mathrm{~V}$ and $100 \%$ when the input voltage is $10 \mathrm{~V}$, so, Equation (8) can be rearranged into Equation (10):

$$
T(t)=K_{T}[v(t)-5]
$$




$$
J_{\text {air }} \frac{d \omega(t)}{d t}+B_{\text {air }} \omega(t)=T(t)=K_{T}[v(t)-5], 5 \leq \mathrm{v}(\mathrm{t}) \leq 10
$$

Figure 5. The linear relationship between input voltage and air pressure difference under the constant supply pressure.

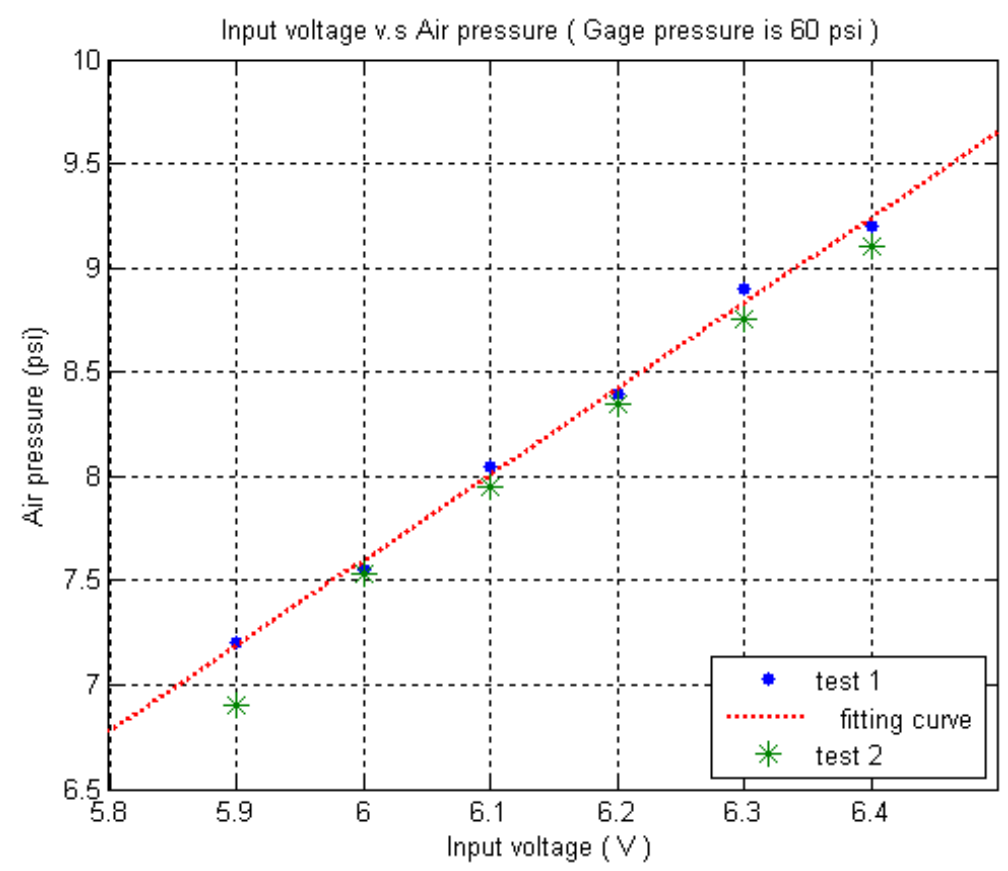

Similarly, taking the Laplace transform of Equation (10), Equation (11) represents the first-order transfer function model which relates the vane-type air motor angular velocity response to the voltage input of the proportional servo valve. For simplicity, the vane-type air motor transfer function model can be equivalent to two parameters which are $K_{\text {air }}$ and $T_{\text {air }}$, which represent the dc-gain and the mechanical time constant of the vane-type air motor, respectively. Through the system identification, the dc-gain $K_{\text {air }}$ is $1,068.89$ and the time constant $T_{\text {air }}$ is 0.1862 of a vane-type air motor. Besides, the model error between $2 \%$ and $16 \%$ due to the compressibility of air and the friction force is non-linear:

$$
G_{\text {air }}(s)=\frac{\omega(s)}{V(s)}=\frac{K_{T} / B_{\text {air }}}{J_{\text {air }} / B_{\text {air }} s+1}=\frac{K_{\text {air }}}{T_{\text {air }} s+1}=\frac{1068.89}{0.1862 s+1}
$$

In the case of the hybrid power platform, the transfer torque of the vane-type air motor and the DC servo motor are transferred to the output shaft of the magnetic powder brake. With the assumption of no disturbance, we can combine Equations (5) and (10), and derive the dynamics of the hybrid power platform as shown in Equation (12). In this equation, the inertia $J$ is the sum of $J_{a i r}$ and $J_{d c}$, the viscosity coefficient $B$ is the sum of $B_{a i r}$ and $B_{d c}$ :

$$
J \frac{d \omega(t)}{d t}+B \omega(t)=K_{T}[v(t)-5]+K_{T} i_{a}
$$




\section{FPGA Speed Controller Design}

The air-electric power hybrid system utilizes the ALTERA DE0 board as its main controller. However, the main challenge for FPGA implementation is improving the precision of the calculation and then saving the resources of the FPGA chip. Furthermore, the modular conception was used to divide a complex system into many subsystems. This modular approach shortens the development time and makes it easier to modify each module.

In this research, the proportional integral (PI) speed controller was adopted in order to accomplish the ECE-40 driving cycle test and have the electric motor rotate at the desired speed when above the determined switch velocity. Through the Ziegler-Nichols rule, we can obtain the initial value of the proportional and integral gains. Then, according to the velocity response, we adjust the proportional and integral gains to obtain better performance for the velocity response. Thus, the PI speed controller based on FPGA was actualized by the Verilog language. The differential algorithm of PI theory is shown in Equation (13):

$$
u(n)=u_{i}(n-1)+K_{p} e(n)+K_{i} e(n-1) d t
$$

Figure 6 shows the block diagram of the PI speed controller. The entire block diagram consists of a frequency divider module, speed measurement module, ECE-40 driving cycle module, error generator module, and PI controller module. In the frequency divider module, the original frequency is $50 \mathrm{MHz}$ on the ALTERA DE0 board that was transformed into $100 \mathrm{kHz}$. The function of the speed measurement module is to calculate the speed of a motor with the optical encoder and increase the measure resolution with the quadrature decoder. The error generator module is to calculate the values of the difference between the ECE-40 command signals and the feedback speed signals. Finally, the control force can be calculated by the PI controller module. During the FPGA speed controller design, the Q-format numerical calculation must be used in the multiplication in order to save the resources of the FPGA chip. According to the Q-format calculation, the output signals would have the same number of bits as the input signals.

Figure 6. The block diagram of the PI speed controller.

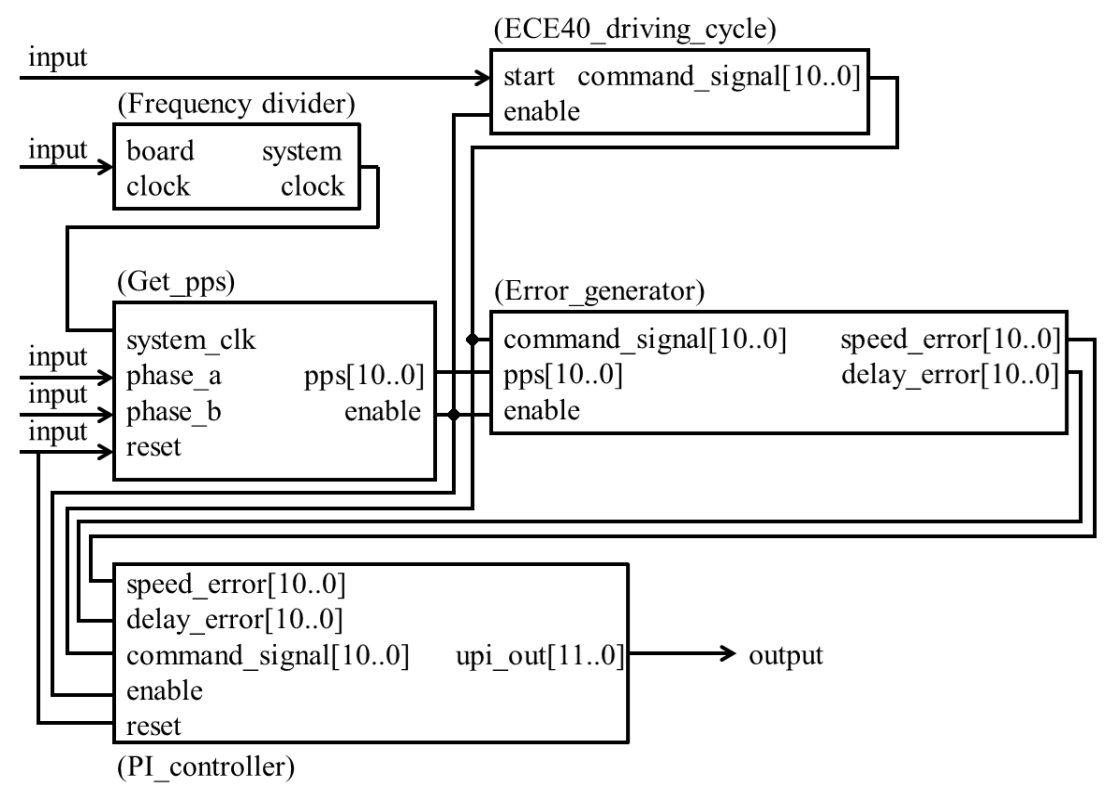




\section{Experimental Results and Discussion}

In order to accomplish the energy comparison of the air-electric power hybrid system shown in the previous sections, the ECE-40 driving cycle (200 s in total) has been used in this research. The ECE-40 European driving cycle has been employed as the motorcycle emissions test procedure (CNS 11386) in Taiwan since 1987. ECE is one kind of steady-type driving cycle, as shown in Figure 7 [14]. In the VHDL programming, the ECE-40 driving cycle is constructed by the look-up table (LUT). In order to simplify the procedure of LUT, the modified ECE-40 driving cycle (red dash line) has been adopted in this experiment.

Figure 7. The ECE-40 driving cycle.

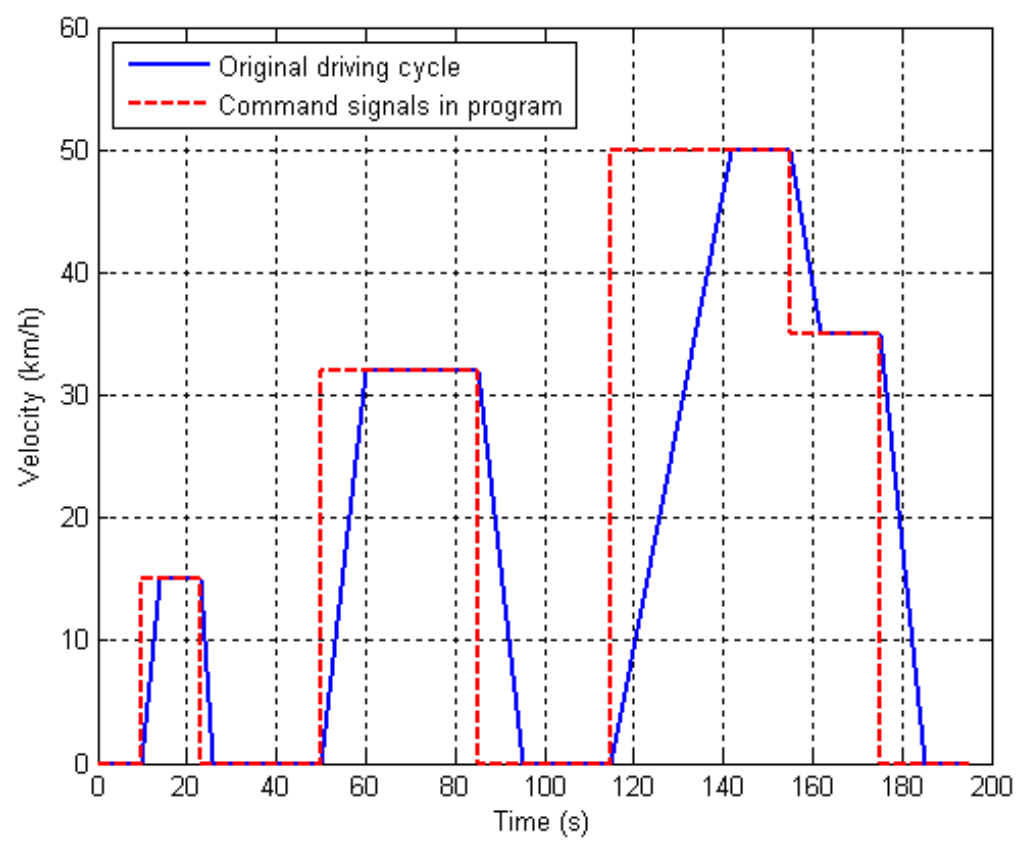

Figure 8. The PI speed control under the air motor mode.

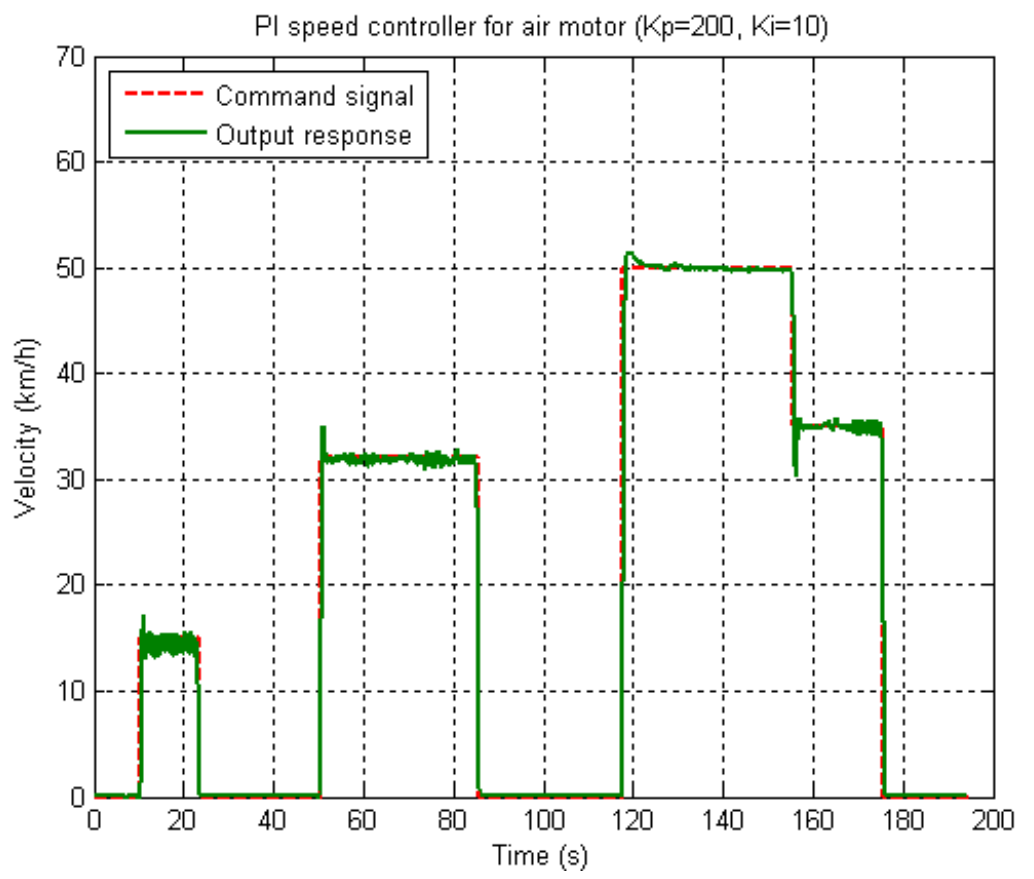


The proposed hybrid power system can be operated in three different modes that include: (1) air motor mode, (2) DC servo motor mode and (3) hybrid power mode. In the air motor mode, the appropriate proportional and integral gain $\left(K_{p}\right.$ is 200 and $K_{i}$ is 10$)$ can be obtained from the system dynamics and the Ziegler-Nichols rule. Figure 8 shows the PI speed control under the air motor mode. From the velocity response, the air motor can rotate at the expected speed with the PI speed controller with the chattering range within $\pm 1 \mathrm{~km} / \mathrm{h}$. Thus, the PI controller based on FPGA is successfully actualized.

Figure 9 also shows the air consumption of the driving cycle test and the total air consumption is about $256 \mathrm{~L}$ under the maximum pressure of about 15 to 20 psi. Similarly, in the DC servo motor mode, the electric charge consumption of the DC servo motor mode is about 530 coulombs.

When the experimental platform is operated in a hybrid mode, the entire procedure as follows: at start up, under low speed conditions, the hybrid power platform is powered by the air motor. When the speed reaches a pre-set switching point $(v=20 \mathrm{~km} / \mathrm{h})$, the DC servo motor will be started and controlled by the PI controller. The ECE-40 driving cycle test under the hybrid mode is shown in Figure 10. There are several phenomena observed in Figure 10: (1) Above the switching point, the DC servo motor is the driving source and the speed has little decrease since the resistance force from the air motor; (2) In the steady state, the chattering range of the air motor is within $\pm 1 \mathrm{~km} / \mathrm{h}$ and $\pm 0.2 \mathrm{~km} / \mathrm{h}$ under DC servo motor drive; (3) In a hybrid mode, the current reduction of the battery is about $18.5 \%$, and then the service life of the battery can be improved. Furthermore, the velocity switch between the air motor and the DC servo motor is very smooth, as observed from the entire speed curve. Therefore, the proposed air-electric power hybrid system is a feasible scheme. Besides, the efficiency of an air motor and a DC servo motor during the driving cycle test as shown in Figure 11. The best efficiency of an air motor (Section 1) is about $20 \%$ and a DC servo motor (Section 2 ) is about $50 \%$.

Figure 9. The air consumption of the driving cycle test.

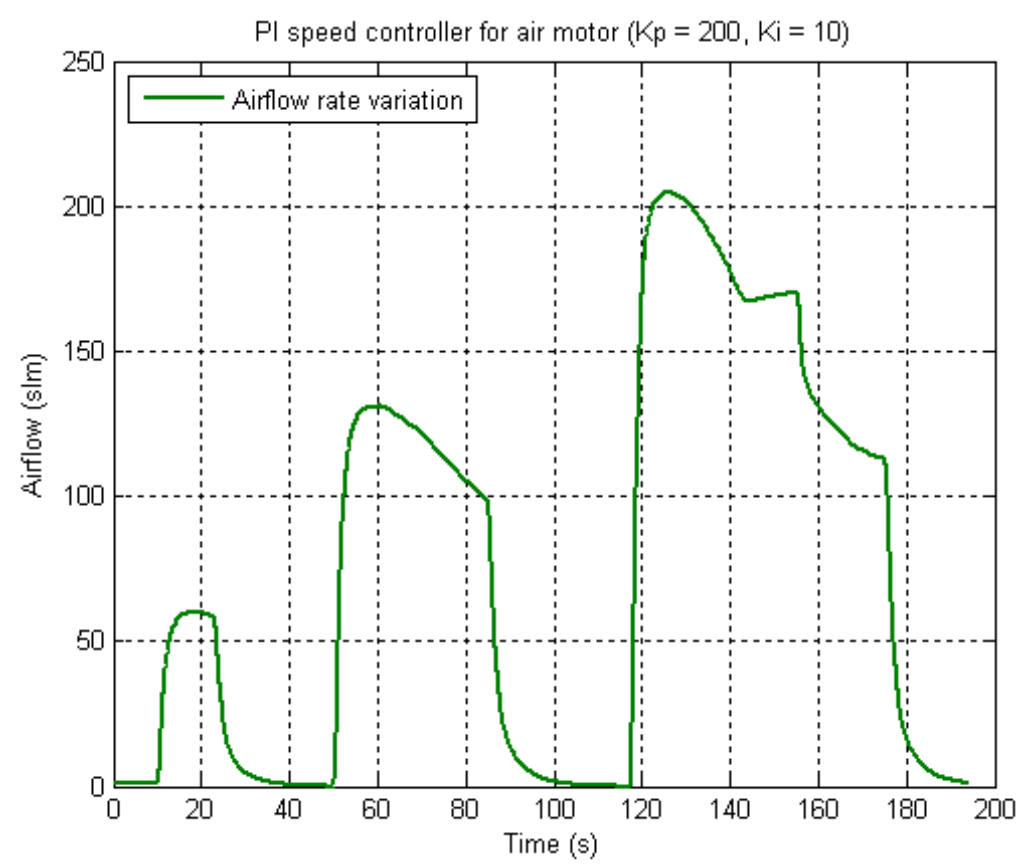


Figure 10. The ECE-40 driving cycle test under the hybrid mode.

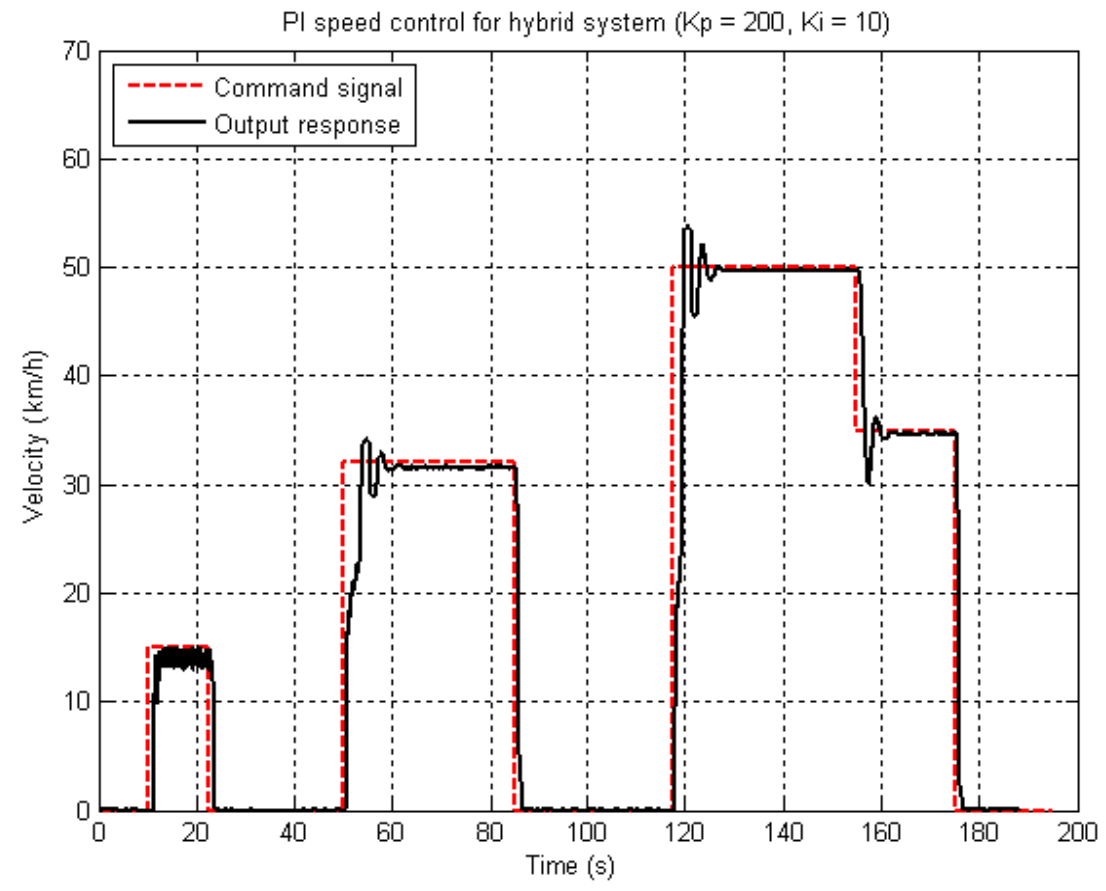

Figure 11. The efficiency of an air motor and a DC servo motor.

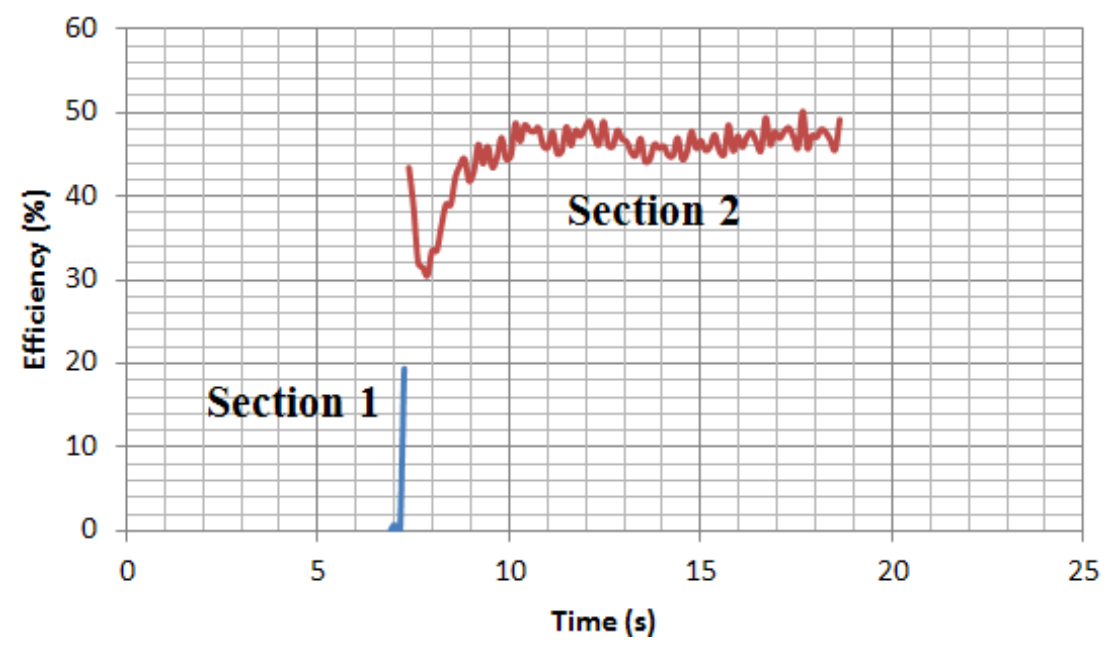

\section{Conclusions}

An air-electric power hybrid system with a FPGA speed controller has been presented and tested in this study. The air assisted power developed in this study can increase the service life of the battery, and thus achieve the objectives of green energy. The experimental data shows a smooth switching between an air motor and a DC servo motor. If we compare hybrid mode to DC servo motor mode, we find the electric energy savings are about $18.5 \%$, which means that the service life of the battery can be improved. Besides, the best efficiency of an air motor (Section 1) is about $20 \%$ and a DC servo motor (Section 2) is about $50 \%$. As for its potential applications, the hybrid system can be applied to electric vehicles to save more electric energy and extend travel distance. In the control performance aspect, the velocity response displays overshoot and chattering phenomena. Therefore, future research will be 
focused on designing the FPGA adaptive controller and the large load condition will be observed in the next experiment, followed by a complete analysis of the entire performance.

\section{References}

1. Ministry of Transportation and Communications of Taiwan Home Page. Available online: http://www.motc.gov.tw (accessed on 5 February 2013).

2. Executive Yuan of Taiwan Home Page. Available online: http://www.ey.gov.tw (accessed on 5 February 2013).

3. Larminie, J.; Lowry, J. Electric Vehicle Technology Explained; John Wiley \& Sons: New York, NY, USA, 2003; pp. 183-212.

4. Chau, K.T.; Chan, C.C.; Liu, C.H. Overview of permanent-magnet brushless drivers for electric and hybrid electric vehicles. IEEE Trans. Ind. Electron. 2008, 55, 2246-2257.

5. Pandian, S.R.; Takemura, F.; Hayakawa, Y.; Kawamura, S. Control Performance of an Air MotorCan Air Motors Replace Electric Motors. In Proceedings of IEEE International Conference on Robotics and Automation, Detroit, MI, USA, 10-15 May, 1999; Volume 1, pp. 518-524.

6. Majumdar, S.J. Pneumatic Systems; Mc-Graw Hill: New York, NY, USA, 1996; pp. 101-104.

7. Shearer, J.L. Study of pneumatic processes in the continuous control of motion with compressed air. ASME Trans. 1956, 78, 233-249.

8. Lan, C.C.; Cheng, C.W. Modeling and Design of Air Vane Motors for Minimal Torque Ripples. In Proceedings of IEEE International Conference on Advanced Intelligent Mechatronics, Montreal, Canada, 6-9 July 2010; pp. 1275-1280.

9. Air Motors Handbook; GAST: Benton Harbor, MI, USA, 1986. Available online: http://www.gastmfg.com/catalogs/airmotorhbk.pdf (accessed on 5 February 2013).

10. Takemura, F.; Pandian, S.R.; Nagase, Y.; Mizutani, H.; Hayakawa, Y.; Kawamura, S. Control of a Hybrid Pneumatic/Electric Motor. In Proceedings of 2000 IEEE/RSJ International Conference on Intelligent Robots and Systems, Takamatsu, Japan, 31 October-5 November 2000; pp. 209-214.

11. Huang, K.D.; Tzeng, S.C.; Chang, W.C. Development of a hybrid pneumatic-power vehicle. Appl. Energy 2005, 80, 47-59.

12. Hsu, Y.Y.; Lu, S.Y. Design and implementation of a hybrid electric motorcycle management system. Appl. Energy 2010, 87, 3546-3551.

13. Monmasson, E.; Cirstea, M.N. FPGA design methodology for industrial control systems-A review. IEEE Trans. Ind. Electron. 2007, 54, 1824-1842.

14. Tzeng, G.H.; Chen, J.J. Developing a Taipei motorcycle driving cycle for emissions and fuel economy. Transp. Res. Part D Transp. Environ. 1998, 3, 19-27.

(C) 2013 by the authors; licensee MDPI, Basel, Switzerland. This article is an open access article distributed under the terms and conditions of the Creative Commons Attribution license (http://creativecommons.org/licenses/by/3.0/). 